\title{
0 estudo de trajetórias de vida nas Ciências Sociais: trabalhando com as diferenças de escalas
}

Paulo Renato Guérios INTR ODUÇÃ̃

(UFPR)

Este artigo propõe uma retomada crítica de diferentes reflexões, feitas em monografias e textos teóricos de autores de diferentes épocas e pertencimentos teóricos, sobre o estudo de trajetórias de vida como uma estratégia para a abordagem de redes sociais. Trata-se aqui, mais do que fazer uma revisão exaustiva do campo, de discutir os ganhos proporcionados pelo uso do método de histórias de vida e, por outro lado, de demonstrar como este método permite ao estudioso complexificar a observação dos fenômenos sociais quando sua análise opera criticamente com as implicações da mudança de níveis de análise. No escopo deste artigo, utilizamos como definições terminológicas aquelas propostas por Maria Isaura de Queiroz (1987), incluindo suas distinções entre: 1. histórias de vida: uma técnica de entrevistas empregada pelo cientista social, que obtém um "relato de um narrador sobre sua existência através do tempo" (op cit: 275); e 2. biografias: textos sobre a história de um indivíduo já objetificados, escritos sem a intervenção de um pesquisador. Definimos aqui também o estudo de trajetórias como as conclusões a que o pesquisador de Ciências Sociais chega a partir do estudo dos materiais obtidos a partir das biografias e das histórias de vida.

Após o uso intenso da metodologia de histórias de vida pelos estudiosos da "Escola de Chicago" entre as décadas de 1920 e 1940, ela desapareceu do campo de interesse dos cientistas sociais por quase quatro décadas, até ser retomada nos campos da História e das Ciências Sociais no final dos anos 1970. No primeiro item do artigo, veremos que, na França, o seu ressurgimento ocorreu inscrito em um debate acerca de suas possibilidades de objetivação.

A seguir, discutiremos como algumas monografias exemplares destes dois 
de análise - questão que, como demonstraremos, parece propor uma solução alternativa ao problema da objetivação, debatido no item anterior.

Por fim, a partir da apresentação dos resultados de um trabalho de pesquisa realizado há alguns anos acerca do compositor brasileiro Heitor Villa-Lobos, buscaremos demonstrar como o trabalho com a variação de escalas possibilita uma apreensão complexificada da trajetória de um ator social específico. Trata-se aqui de empregar criticamente a proposta heurística dos microhistoriadores italianos que, no início da década de 1980, atentaram a uma análise em nível micro das complexidades das dinâmicas sociais, sem no entanto desconsiderar o modo pelo qual estes eventos em pequena escala se relacionavam com eventos macrossociais. No caso aqui tratado, o contraste entre nosso esforço de pesquisa e aqueles de outros estudiosos, em cujos trabalhos as especificidades da variação de escalas foram desconsideradas, pretende mostrar, a partir de um caso empírico, como o potencial heurístico do método de histórias de vida pode ser otimizado quando as injunções desta variação são levadas em consideração na análise.

\section{A HISTÓRIA DA HISTÓRIA DE VIDA E OS DILEMAS DA OBJETIVAÇÃO}

A metodologia da história de vida, segundo estudiosos que se dedicaram ao tema (Bertaux, 1999 [1980]: 1, 1997: 7; Becker 1986: 105), teria surgido nas Ciências Sociais na década de 1920, com os estudos da chamada "Escola de Chicago". As entrevistas de caráter biográfico possibilitaram, para estes estudiosos, abordar temas como as mudanças sociais relativas a processos migratórios (como no caso do clássico The Polish Peasant in Europe and America, de Thomas e Znaniecki, frequentemente considerado o primeiro trabalho a utilizar relatos autobiográficos como material de pesquisa) e as carreiras de indivíduos tidos como desviantes ou delinquentes (em estudos como The Jack Roller, de Clifford Shaw) - ou seja, temas de pesquisa em que o pertencimento social dos sujeitos observados não é dado a priori.

Após a produção de um grande número de estudos sob a égide da "Escola de Chicago", o uso deste método sofreu um forte declínio. Segundo Becker (op cit: 109), o desenvolvimento de teorias mais "abstratas", que “insistiam mais sobre as variáveis 'estruturais' e análises sincrônicas funcionais do que sobre fatores que se manifestavam na vida e experiência do indivíduo" foi o grande responsável pelo abandono do método, que "parecia inadaptado no quadro de estudos que insistiam sobre as propriedades dos grupos sociais e suas conexões" (id, ibid). ${ }^{2}$

No final da década de 1970, o uso do método de histórias de vida retornou com força na França, a partir do surgimento de um relatório de pesquisa do estudioso Daniel Bertaux. ${ }^{3}$ Apesar de não publicado, este relatório teve uma "influência inegável sobre uma geração de pesquisadores recrutados nos anos setenta" (Peneff, 1994: 26). As principais ideias de Bertaux foram publicadas logo a seguir, em 1980, em um artigo fundamental chamado "L'approche biographique: sa validité méthodologique, ses potentialités" (Bertaux 1999 [1980]). Neste texto, 
Bertaux defendeu que um "enfoque biográfico" deveria utilizar relatos de vida, empregando aí a palavra inglesa story para designar "a história de uma vida tal como a conta a pessoa que a viveu" (op cit: 3). Esta proposta analítica dispensava a análise de fontes externas ao discurso do sujeito que reconstrói suas vivências. Tal esforço de objetivação através do recurso a "outras classes de documentos" incorreria, para Bertaux (id, ibid) em uma “orientação 'tecnocrática' (...) na qual se desenvolve plenamente uma vontade incontrolada de saber".

É possível que a defesa feita por Bertaux de um método que abrisse mão de referentes externos às histórias de vida dos entrevistados esteja ligada ao fato de que, especialmente em seu campo de pesquisa (a sociologia do trabalho) e na época da escrita de seu artigo (quando o paradigma marxista era dominante), a proposta de um "novo processo sociológico, um novo enfoque", que buscava se anunciar desde o princípio como "portador de futuro" (op cit: 3), pudesse se dar apenas a partir de um confronto direto ao paradigma então vigente. Ao mesmo tempo, entretanto, para inserir seu debate em seu contexto de enunciação, Bertaux se preocupou em defender no mesmo artigo a cientificidade e a objetividade de seu "enfoque". Para tanto, segundo afirmou, os "relatos de vida" deveriam ser obtidos com informantes cujos perfis fossem "conscientemente diversificados", e deveriam ser repetidos até atingir um "ponto de saturação" - ou seja, deveriam ser obtidos em um número significativo de casos, a partir do qual a representatividade da amostra fosse garantida. Quando alcançada, esta "saturação" conferiria, em suas próprias palavras, "uma base muito sólida à generalização, (...) cumprindo no enfoque biográfico exatamente a mesma função que tem a representatividade da amostra na pesquisa por questionários" (op cit: 9).

A partir da publicação deste artigo, Bertaux tornou-se paulatinamente o principal nome do campo de estudos de histórias de vida, e sua obra teve impacto internacional. ${ }^{4} \mathrm{Na}$ medida em que sua influência crescia, sua opção pela análise de "relatos de vida" sem recurso à objetivação por documentos externos passou a polarizar os debates acerca do assunto. Em 1986, Pierre Bourdieu dedicou ao assunto um dos números de sua prestigiosa revista, a Actes de la Recherche en Sciences Sociales. Ao mesmo tempo em que este número temático reunia artigos de pesquisadores como Michael Pollak, Nathalie Heinich, Pierre Pénisson e outros, que se esforçavam por redefinir diretrizes para o uso de histórias de vida como método nas ciências sociais, Bourdieu, em um curto e incisivo texto, lançou uma forte crítica sobre o que chamou de "ilusão biográfica". Denunciando desde o início que "a história de vida é uma dessas noções de senso comum que entraram de contrabando no universo acadêmico", Bourdieu (1986: 69), desqualificou tanto o método como seu objeto - de fato indiscerníveis segundo seu ponto de vista. O objetivo de Bourdieu era criticar nos estudos do "enfoque biográfico" a ausência do que considerava uma necessária objetivação dos dados. Para tanto, propunha que os esforços acerca do assunto fossem transformados em "estudos de trajetórias", utilizando uma metáfora que viria a se tornar célebre:

a análise crítica [destes] processos sociais (...) conduz à construção da noção de trajetória como série de posições ocupadas por um mesmo agente (ou um mesmo grupo) em um espaço ele mesmo em devir e submetido a incessantes transformações. Tentar compreender uma vida como uma série única e suficiente em si mesma de eventos sucessivos sem outra ligação que a associação a um "sujeito" cuja constância é apenas aquela de um nome próprio é quase tão absurdo quanto tentar explicar um trajeto no metrô sem levar em conta a estrutura da rede, ou seja, a matriz das relações objetivas entre as diferentes estações. (op cit: 71) 
Percebe-se como a crítica de Bourdieu diz respeito justamente à ausência, nos estudos de história de vida realizados por Bertaux e seus seguidores, de um esforço sociológico para situar a trajetória da vida estudada frente às condições concretas de existência a ela subjacentes.

Em artigo escrito oito anos mais tarde, Peneff (1994: 26) atribuiu ao texto de Bourdieu a "marca de uma parada, o signo de uma mudança intelectual": para ele, alguns anos depois o "enfoque biográfico" teria terminado seu "ciclo de vida", após ter durado cerca de quinze anos, "a duração média de existência de uma paixão teórica ou metodológica na sociologia" (id, ibid). Sintomaticamente, entretanto, um artigo publicado em 2010 daria como terminada a influência do artigo de Bourdieu. No texto, chamado "Pour en finir avec I"illusion biographique" ", Nathalie Heinich critica o que considera serem os excessos do texto de Bourdieu: uma indistinção entre biografia como material empírico e biografia como método; uma pressuposição subjacente de que, por ser socialmente construído, o discurso biográfico seria falso; a desconsideração, como questão de pesquisa, do esforço de constituição de um relato coerente por parte do sujeito que fala; e um excesso explicativo, que deixaria de lado o esforço pela compreensão (nos termos de Weber) da fala daquele que relata sua história de vida.

Estas leituras opostas acerca da polêmica levantada por Bourdieu parecem dizer menos respeito a sua distância no tempo (de 16 anos) do que às posições teóricas de seus autores. De fato, Peneff dedica parte de seu artigo a discutir como o cientista social pode ter "controle" sobre o conteúdo do relato biográfico, evitando ser "manipulado" e acedendo assim a uma "confiabilidade julgada satisfatória" acerca da "validade" dos dados obtidos (Peneff, op cit: 29). Para tanto, o "melhor controle" seria obtido pela "manifestação, pelo sociólogo (em suas reações, questões, colocações) de um bom conhecimento da época e do meio evocados na entrevista (...), o conhecimento histórico, econômico, demográfico, político das situações" (id, ibid). A posição epistemológica de Peneff aproxima-se assim, em sua defesa de uma completa objetivação externa dos dados, àquela de Bourdieu. Já a posição oposta, defendida por Heinich, defende um ponto de vista muito mais próximo ao de Bertaux:

Em uma perspectiva explicativa e objetivista, o relato biográfico é apenas uma ferramenta, em falta de uma melhor, para atingir a realidade à qual ele se refere, mesmo que a deformando; enquanto em uma perspectiva compreensiva (que apenas seria subjetivista com a condição de se abster de toda a comparação entre diferentes experiências e de toda tentativa de perceber a estruturação do espaço de possíveis tal como ele se oferece aos atores) este relato faz parte da matéria mesma da investigação: não apenas o que permite compreender, mas também o que deve ser compreendido. (Heinich 2010: 426).

Em contraposição a um esforço "explicativo", Heinich defende a adoção de um esforço "compreensivo"; ao invés de remeter os relatos de vida às condições concretas de existência, propõe remetê-lo a outros relatos e à compreensão que o sujeito tem do espaço de possibilidades em que suas vivências estão inscritas.

Deste modo, tudo indica que os textos de Bertaux, ao propor uma leitura das histórias de vida que não recorre à explicação sociológica, e de Bourdieu, ao propor uma leitura das histórias de vida que não recorre à compreensão sociológica, marcaram o campo de discussões acerca do uso deste método nas Ciências Sociais na França. Ainda hoje, o debate aparece radicalmente ligado a uma ou outra postura teórica. ${ }^{5}$ 
Deve-se destacar que, em artigo publicado em 1990, Passeron já defendia o emprego de uma posição menos polarizada neste debate:

a superação, atualmente observável em numerosas pesquisas, das formas mais mecânicas ou mais abstratas de um naturalismo determinista constitui indiscutivelmente um avanço teórico; mas com a condição que se faça melhor do que aquilo que se quer superar, ou seja, que se some [o estudo dos] constrangimentos à interpretaçẫo (Passeron 1990: 4).

Contudo, para além da posição de Passeron, que foi publicada antes da discussão aqui colocada e que portanto já era conhecida dos autores aqui citados, o problema parece persistir porque, de fato, toda esta discussão remete a um nó epistemológico das Ciências Sociais, muito discutido mas que parece constitutivamente insolúvel: tanto a divisão entre explicação e compreensão quanto o problema da trajetória de um indivíduo em uma sociedade geram uma ressonância com a discussão entre objetivo e subjetivo, parte e todo, que parece ainda estar subjacente a boa parte das discussões nesta área. O estatuto do individual em Ciências Sociais é remetido ao subjetivo, ao particular, logo ao não generalizável. Já o que é relativo à sociedade remete ao objetivo, àquilo que diz respeito a uma coletividade, logo ao generalizável. Mesmo o trabalho tido como fundador do método, de Thomas e Znaniecki, já se deparava com a necessidade de justificar a cientificidade de um método das ciências sociais que enfocava indivíduos. ${ }^{6}$

Entretanto, se colocarmos como nosso objetivo não a busca de uma maior cientificidade, mas sim a recolocação das questões de pesquisa em outros termos, possibilitando um tratamento dos dados de campo que não sofra com as limitações impostas por uma construção dilemática das questões, percebemos que, justamente por colocar-se à cavaleira em relação à dualidade indivíduo-sociedade, o método de histórias de vida pode oferecer, se levado a cabo com consistência, um bom locus de trabalho em prol desta tarefa. Ao tomar por foco de estudo a trajetória de uma pessoa nos ambientes sociais de que participa, ao oferecer a oportunidade de questionar como cada sujeito vive ligado a redes de interdependência (Elias 1994) que se estendem além de seu pertencimento social imediato, estes estudos deparam-se frontalmente com a questão da relação entre o individual e o social, entre o pequeno e o grande, entre a parte e o todo. E foi nesta área de trabalho que algumas indicações de caminhos para a superação deste dilema surgiram, em algumas monografias e textos teóricos de que trataremos a seguir.

\section{TRAJETÓRIAS E OS JOGOS DE ESCALAS}

Uma questão chave acerca dos estudos que empregam histórias de vida diz respeito às conexões estabelecidas, nestes trabalhos, entre uma trajetória individual e o meio social em que ela se desenrola - questão esta que espelha as dificuldades do dilema do dualismo sociedade-indivíduo. Como afirma Giovanni Levi (1989: 1331), o uso da noção de "contexto" na tentativa de resolver estas questões é em geral problemático, pois "o contexto é em geral pintado como rígido, coerente, servindo como um pano de fundo imóvel para explicar a biografia". 
De fato, em vários estudos de trajetórias, esta ligação é traçada através de uma remissão abstrata do ator social ao meio em que ele se insere. $O$ pressuposto subjacente a estes estudos, dificilmente explicitado como tal, é de que o pertencimento a um dado grupo implica inevitavelmente em inflexões unívocas nas trajetórias de todos os seus membros. Ocorrem aí duas ordens de problemas: por um lado, é em geral o analista quem arbitra quais eventos ou características dos ambientes sociais enfocados são relevantes para análise; em segundo lugar, pressupõe-se que todo o grupo foi submetido de modo homogêneo a estes eventos ou características especificados pelo analista. Já os estudos subjetivistas de histórias de vida privilegiam a observação exclusiva dos discursos de um dado indivíduo, desconsiderando a regulação operada sobre ele pelos meios sociais a que está ligado. Neste item, buscaremos demonstrar que propostas analíticas que levam em consideração as implicações das diferenças de escalas (micro e macro) na produção de legibilidade sobre os fenômenos sociais possibilitam neutralizar os efeitos das limitações impostas por estes dois tipos de démarche no estudo de trajetórias de vida.

Comecemos falando sobre uma monografia de exceção, que nos parece antever esta solução precocemente. Em Worker in the cane, pesquisa publicada em 1960, Sidney Mintz enfoca as relações entre a trajetória de vida de um trabalhador porto-riquenho e o ambiente social em que ela se desenrola. Desde o início, Mintz destaca que seu personagem, Taso, "não é um 'típico' nada - nem um típico homem, nem um típico porto-riquenho, nem um típico trabalhador da cana de classe baixa porto-riquenho. (...) Ele não se considera representativo de nada, e está certo ao fazê-lo" (Mintz, 1960: 11). Ao destacar a univocidade da trajetória de seu informante, Mintz já elimina a possibilidade de estabelecer uma conexão abstrata entre sua trajetória e o meio social em que ele vive. Seu esforço passa a ser então "seguir a trilha da existência de um único homem no tecido da história de sua aldeia" (op cit: 26).

É interessante notar que, em seu estudo, Mintz não lança mão do uso de estatísticas, nem coteja a trajetória de Taso com a de outros sujeitos de seu meio, nem busca explicar sua existência objetivando diretamente seu pertencimento a um grupo. Mesmo assim, ele é capaz de emprestar legibilidade sociológica à trajetória de Taso ao explorar cuidadosamente a história e a inserção de sua aldeia no sistema colonial que os Estados Unidos impuseram em Porto Rico. Como ele afirma,

um olhar através das lentes da história mostra o modo pelo qual um povo - um grupo social, uma subcultura, uma comunidade ou um país inteiro - abre-se, através de importantes mudanças econômicas, políticas e ideológicas, a novas percepções, novos padrões de comportamento e crença, novos modos de ver o que ocorre com eles. (...) Os eventos da vida de Taso correm paralelos às grandes mudanças que ocorrem ao seu redor. Em cada ponto é possível ver como ele tomou todas as vantagens possíveis das oportunidades que sua sociedade lhe oferecia, de acordo com suas próprias necessidades e seu temperamento. A mudanças em si não explicam a trajetória particular de sua vida; elas são antes as condições sob as quais sua vida tomou uma forma característica. (op cit: 253, 262)

O que torna a análise de Mintz eficaz frente a seus objetivos é, por um lado, o foco na realidade imediata vivida por Taso - a história de Porto Rico interessa apenas nos impactos concretos que tem sobre a aldeia e a vida de seu personagem - e, por outro lado, a atenção a suas ações, e não às leituras morais que se depreende 
delas. O estudo sociológico feito ao redor de seu personagem não leva a cabo uma conexão simplista e direta entre o indivíduo e o meio social, mas permite, ao contrário, tornar a trajetória de Taso compreensível ao colocar em relevo elementos que explicitam suas condições de possibilidade. As conexões entre as ações de Taso e a história de sua aldeia e de seu país são demonstradas, e traçadas a partir de evidências concretas. Evita-se assim assimilar a trajetória do sujeito observado sob grandes eventos, que ocorrem em outra escala e com os quais ela não guarda uma relação demonstrável empiricamente.

O trabalho de Mintz porta traços de alguns desenvolvimentos que ocorreriam no campo da História uma década mais tarde. Estes desenvolvimentos foram reunidos sob a denominação de "microhistória", e englobaram as discussões surgidas entre historiadores italianos no sentido da "redução da escala de observação, em uma análise microscópica e em um estudo intensivo do material documental" (Levi 1992: 136). O foco em acontecimentos locais conduziu estes pesquisadores a perceber que "a realidade normativa (...) oferece muitas oportunidades de interpretações e liberdades pessoais [através das] brechas e contradições dos sistemas normativos" (op cit: 135). A redução de escala "para propósitos experimentais" passou então a "revelar fatores previamente não observados" (op cit: 138). A microhistória propôs assim um movimento na direção de fundamentos empíricos para uma nova história, que fosse capaz de compreender melhor os dilemas, contradições e impasses de um período histórico através da vivência de indivíduos singulares, evitando operar com generalizações como as que eram comumente feitas neste campo acerca de "épocas" ou "idades".

Em uma de suas monografias, por exemplo, Giovanni Levi (2000), ao reduzir sua escala de observação para uma área localizada, pôde questionar a pressuposição de que os preços de terra na Itália do século XVII eram submetidos a forças impessoais de mercado. Sua pesquisa em um contexto local indicou que estes preços variavam segundo as relações de parentesco entre as partes envolvidas e que, assim, relacionamentos pessoais cumpriam papel fundamental para seu estabelecimento. Adicionalmente, este estudo nos é de grande interesse por tratar, a partir deste ponto de vista metodológico, da trajetória de um indivíduo e das estratégias traçadas por ele no sentido de manter sua posição de poder local frente a uma dada situação de sua aldeia no Piemonte - que ao mesmo tempo estava confrontada ao processo de constituição do Estado italiano. A reconstrução de Levi permite que acompanhemos tanto a vida política e as relações sociais locais da aldeia quanto suas articulações com processos de grande escala, tais como o envolvimento da população desta região em uma guerra com a França de Luís XIV. Percebe-se assim, como bem observa Jacques Revel no prefácio às edições francesa e brasileira da obra, "a modulação local da grande história", que

se inscreve em acontecimentos minúsculos: a multiplicação das vendas e compras de terra, o movimento incessante (...) do crédito; o destino coletivo dos conjuntos familiares, com seus ganhadores e perdedores; a luta pelo prestígio e pelo poder local (...). Individualmente, nenhum destes detalhes tem a menor importância. Tratados juntos, permitem reconstruir os contornos de um grande jogo social e político que é o verdadeiro assunto deste livro. Sem dúvida, nenhum dos habitantes de Santena (...) é capaz de influir no destino da guerra e nem mesmo nos progressos do Estado administrativo e fiscal. Mas todos, e cada um em seu lugar, se esforçam para encontrar uma resposta para os problemas que lhes vêm da grande história (Revel 2000: 25 - 26). 
O indivíduo cuja trajetória é traçada por Levi tem sua história de vida reconstituída a partir de sua inserção no projeto político local de seu pai, e das consequências dessa inserção frente ao equilíbrio de forças da aldeia com a unidade que a engloba (o ducado). Sua existência será assim compreendida a partir do recurso às diferentes escalas de análise, do micro ao macro, e à importância relativa de cada uma delas na definição do campo de possíveis vivido por este ator social.

Assim, se é fato que "é ao nível de uma região ou de uma aldeia (...) que o indivíduo teve experiências, (...) pesou possibilidades ou obteve informações que apoiaram suas escolhas, [e não] na situação nacional, nos quadros históricos, em geral muito amplos (...) que o sujeito encontrou e defrontou as 'relações objetivas' " (Peneff op cit: 29), o ganho teórico da microhistória está em nos lembrar que

cada ator histórico participa, de maneira próxima ou distante, de processos de dimensões e níveis variáveis, do mais local ao mais global. Não existe portanto hiato, menos ainda oposição, entre história local e história global. O que a experiência de um indivíduo, de um grupo, de um espaço permite perceber é uma modulação particular da história global. Particular e original, pois o que o ponto de vista microhistórico oferece à observação não é uma versão atenuada, ou parcial, ou mutilada, de realidades macrossociais; é (...) uma versão diferente (Revel, 1998: 28).

Deste modo, o pesquisador não deve optar entre uma versão macro ou micro da análise de um dado processo social. O que a microhistória coloca em destaque é o fato de que a análise microssocial é esclarecedora porque é a mais complexa, ou seja, porque leva em consideração a complexidade das escolhas dos atores permitindo, ao mesmo tempo, distinguir os diferentes níveis de contextos pertinentes para a análise (Revel op cit: 32; Bensa 1998: 45).

Esta proposta analítica parece então responder à necessidade, descrita no item anterior, de que a questão das relações entre o indivíduo e o meio social seja recolocada em outros termos. A proposta de Norbert Elias $(1980,1994)$, que sugere o uso dos termos "relação de interdependência" e "configuração social" para superar estes dilemas, parece ser uma das boas soluções para esta necessária "reorientação do pensamento" do cientista social no sentido de destacar o "caráter processual das relações entre pessoas interdependentes (Elias 1980: 88). O que a proposta da microhistória adiciona a este esforço é uma metodologia capaz de resolver estas questões, como coloca Levi (1992: 161), "em termos mais formais".7

\section{O CASO DE HEITOR VILLA-LOBOS: USOS ANALÍTICOS DA HISTÓRIA DE VIDA}

Vejamos agora um exemplo empírico que nos permita avaliar concretamente o rendimento da proposta de estudar histórias de vida a partir da consideração das diferentes escalas pertinentes para a análise. Para tanto, iniciaremos com uma breve revisão de alguns estudos da trajetória de vida do compositor brasileiro Heitor Villa-Lobos feitos a partir de outras perspectivas teóricas e metodológicas. Discorreremos acerca das diferentes estratégias de exploração seguidas por estes autores, assim como sobre os diferentes pressupostos que os guiaram em seus 
trabalhos e sobre os diferentes objetivos de suas propostas analíticas. No próximo item, estas perspectivas serão confrontadas com as possibilidades analíticas oferecidas por um estudo de trajetória de vida que leve em consideração as consequências heurísticas da variação de escalas.

Dentre os autores ligados às Ciências Sociais que se dedicaram a discutir a trajetória de Villa-Lobos, selecionaremos aqui três, escolhidos não tanto pela relevância de seus textos sobre o compositor - ou de sua posição no campo intelectual - quanto pela possibilidade de tomá-los como representantes de paradigmas analíticos distintos para a abordagem de trajetórias sociais. ${ }^{8}$

Em primeiro lugar, abordemos os comentários de Gilberto Freyre acerca de Villa-Lobos. Em 1982, Freyre foi convidado pela viúva do compositor para proferir uma conferência sobre ele. Nela, o sociólogo afirma que Villa-Lobos tinha realizado a "façanha" de realizar-se como intérprete "dos componentes de uma cultura como a brasileira, sentindo-se não só em incivilizados ou, ainda, em primitivos, ou naqueles que ainda não atingiram em cultura um grau de civilização, como em civilizados" (Freyre 1982: 3, grifos adicionados). "Projetando-se empaticamente" e "penetrando" em uma "virgindade cultural brasileira" ainda não detectada, Villa-Lobos teria conseguido "universalizar" os elementos mais "primitivos" da "cultura brasileira". Essa empatia, no entanto, "esse poder extraordinaríssimo de certos criadores (...) de interpretarem o que está fora deles" ao se projetarem "nesses outros eus, eus fora do verdadeiro eu" (op cit: 2) foi realizada por um "eu" especificamente carioca, um "eu" moldado sob o impacto de "influências sócio-musicais" quando ainda jovem no Rio de Janeiro. Como Freyre já dizia no título de um artigo escrito logo após a morte do compositor, Villa-Lobos era "pan-brasileiro mas carioca":

Vocês vejam como os impactos da formação de um indivíduo de superior talento parecem predispor esse indivíduo para certa vocação e entretanto ele se realiza noutra vocação. Direi que, no caso de Villa-Lobos, ele parece ter sido influenciado, como carioca, em grande parte, por impactos sociais, e direi que esses impactos sociais se tornaram nele sócio-musicais. É um assunto para um estudo detalhado do que se pode chamar, ao lado de uma sócio-lingüística, uma sócio-musicalidade.

Suponho que muitos foram os impactos sobre a formação do menino Villa-Lobos. Desse impacto de convivência carioca, de convívio jovial carioca, não especificamente já musicais, porém mistos, sócio-musicais, é que ele parece ter surgido. De modo que pode-se admitir, de Villa-Lobos, que sobre o nascido e crescido carioca viriam a influir, em suas vocações empáticas ou, pelo menos, sobre sua predisposição empática, sua tendência a cariocamente compreender, dentro do que era ele próprio, outros eus, ao ponto de poder traduzir ou interpretar esses outros eus. Vamos imaginar que, como sócio-músico, ele começou a absorver em si influências sócio-musicais vindas para um morador, como ele, quando plasticamente jovem, de um Rio de Janeiro, capital, na época do Brasil, como sons não abstratamente sons porém sons sociais confluentes, que viessem a confluir nele, carioca, dando-lhe uma perspectiva trans-carioca, ultra-carioca, pan-brasileira (Freyre 1962: 10).

Segundo Freyre, então, sob impacto do "convívio jovial carioca" Villa-Lobos teria "absorvido sons" em um Rio de Janeiro que centralizava todos os sons do Brasil. Mas, para ele, estes sons foram percebidos através de uma essência social - utilizados após já filtrados pela "sensibilidade social" do compositor: "sons não abstratamente 
sons porém sons sociais". Construídas através desse processo, as músicas de Villa-Lobos são a representação artística do Brasil social, compostas por alguém portador de uma dupla sensibilidade (um "sócio-músico") que, a partir de sua essência social carioca, percebe através de um filtro social a essência musical brasileira.

A análise de Freyre considera então que a obra de Villa-Lobos resulta de uma habilidade de colocar-se no lugar do outro, sentindo o que ele sente e captando sua essência ao longo de um processo de socialização: Freyre conecta um indivíduo - Heitor Villa-Lobos - com um meio social abstrato e totalizado que o engloba. Villa-Lobos seria capaz de, a partir de uma sensibilidade individual privilegiada, moldar suas produções musicais de acordo com este ambiente social englobante.

Outra é a proposta do etnomusicólogo norte-americano Gérard Béhague. Calcado na leitura de Clifford Geertz, cujo trabalho cita como sua referência heurística de base, Béhague vai procurar interpretar nas partituras de Villa-Lobos a essência de sua "brasilidade". Em seu livro, cujo nome é Heitor Villa-Lobos. The Search for Brazil's Musical Soul, Béhague analisa a substância musical de inúmeras obras do compositor. Como epígrafe da análise, está a seguinte citação de Geertz: “O problema principal apresentado pelo fenômeno agudo da força estética, venha ela na forma que vier ou como resultado da habilidade que for, é como localizá-la dentre os outros modos de atividade social, como incorporá-la na textura de um padrão particular de vida". Para Béhague, então, a arte aparece enquanto problema social quando se tenta estabelecer relações entre a substância estética das obras de arte e a substância social das "redes de significados" que compõem uma "cultura". Villa-Lobos seria, assim, um compositor capaz de absorver esta cultura e devolvê-la, reelaborada, em suas composições.

Comentemos, por fim, o trabalho de um outro autor que enfocou uma parte da trajetória de Villa-Lobos a partir de uma tendência analítica representativa nas Ciências Sociais. Em O coro dos contrários: a música em torno da semana de 22 (1983 [1974]), o pesquisador José Miguel Wisnik, do Departamento de Letras da Universidade de São Paulo, faz uma leitura das relações de Villa-Lobos com a Semana de Arte Moderna calcada em instrumentos analíticos destas Ciências. Tratarei aqui apenas de algumas linhas gerais da análise proposta pelo autor.

O instrumental utilizado por Wisnik advém da Sociologie de la musique de Adorno: o estudioso procura, através da análise da substância musical das obras apresentadas por Villa-Lobos na Semana de Arte Moderna, detectar a significação social que estaria organicamente presente em seu interior, com o "social" também entendido como uma totalidade que engloba os indivíduos. Em suas palavras: "procuro fazer um levantamento geral dos procedimentos técnicos que essas obras põem em circulação, para procurar definir, em última análise, que tipo de orgânica as preside e a que sentido ideológico (ou sentidos) podem corresponder" (op cit: 141). Uma cuidadosa leitura estética de algumas obras se segue, durante a qual o autor encontra elementos de uma "selvageria" característica de Villa-Lobos misturados ao "refinamento" de Debussy; isso é identificado exemplarmente em um trecho das Danças características africanas que é "baseado modalmente nas escalas de Debussy [no caso, a escala de tons inteiros] e ritmicamente no gingado da síncope" (op cit: 151).

A música de Villa-Lobos estaria então em uma "área que toca os limites do extremamente primitivo e do extremamente requintado, onde contraditoriamente, a radicalização de uma tendência da cultura [ou seja, o 
movimento que leva à quebra tonal de Stravinski] conduz por um momento a reapresentar o som em estado natural [o uso do 'som puro', que Stravinski pregava]" (op cit: 166). Já o modernismo brasileiro tinha seu eixo ao redor da "tensão entre futurismo e primitivismo", entendidos como "adoção de técnicas cosmopolitas concomitantes com a representação de um mundo mágico e selvagem" (grifos do autor); as obras de Villa-Lobos, portanto, estariam tocando exatamente nesse ponto, o que explicaria sua grande aceitação pelos críticos modernistas.

Não se tratava, no entanto, para Wisnik, de uma pura confluência de expectativas. As obras apresentariam tanto um significado estético (percebido pelos promotores da Semana) quanto um significado social englobante: "as forças desencadeadas nas peças de Villa-Lobos tocam nesse campo de possibilidades, onde o requinte da evolução das forças produtivas de uma sociedade tendente ao refinamento da tecnificação se junta (...) à emergência de um denso e diversificado mundo de possibilidades da natureza". Assim, a produção de VillaLobos após 1922, segundo Wisnik, além de ocorrer "como resultante (...) de sua complexa personalidade" (ou seja, do indivíduo Villa-Lobos),

resulta também de uma coordenada coletiva, que é a necessidade de representar a imagem de uma natureza pujante de recursos, a evidenciar as enormes potencialidades da nação, a projetar uma visão positiva das suas possibilidades. O problema é complexo, mas pode ser tratado a partir de uma ideia de Adorno, segundo a qual o talento se forma no encontro de certas linhas tendenciais de necessidades presentes num meio social, que o plasma conforme suas expectativas (op cit: 167).

Desse modo, a música de Villa-Lobos antes de 1922 teria agenciado técnicas de Debussy como uma maneira de libertar um nacionalismo que já estava presente. Já a música posterior a 1922 seria o resultado da combinação do indivíduo Villa-Lobos com um ambiente social englobante que o teria "plasmado" de acordo com a necessidade de representar um país voltado para o futuro, com energia para realizar-se, com potencial para explodir. Villa-Lobos, enfim, moldado por esse "social" que englobaria a todos, acaba por ser o próprio país em forma de música.

Se por um lado Wisnik não opera com a noção de uma "essência" que estaria sendo incorporada (empaticamente, via "cultura" ou via socialização) por Villa-Lobos, o compositor aparece também em seu trabalho como "fruto de seu meio". Este "meio social" é tomado, por Wisnik, de forma totalizada e abstrata. O período de "progresso" por que passava o Brasil estaria "plasmando" a substância musical produzida por Villa-Lobos. Mas note-se que o "social" que teria "plasmado" a música de Villa-Lobos é decodificado pelo autor como sendo as próprias ideias modernistas: Wisnik toma uma das posições presentes em um campo de lutas estéticas como a totalidade da "arte brasileira" - e mesmo do Brasil - naquele momento histórico. A análise de Wisnik exime-se de ver as pequenas interações que influíam sobre a trajetória de Villa-Lobos, assim como os movimentos mais abrangentes de relações entre os artistas brasileiros e estrangeiros nesta época, e engloba o estudo da trajetória do compositor brasileiro sob as ideias dos modernistas. Ela apaga, enfim, o próprio Villa-Lobos enquanto agente, ao não ver o tanto que ele próprio trabalhou para conseguir influir nos rumos de sua própria trajetória. 


\section{HEITOR VILLA-LOBOS: A LUTA PELA PREDESTINAÇ̃̃O}

As leituras acerca de Villa-Lobos resenhadas acima são limitadas devido ao fato de operarem com a totalização do ambiente social em que se desenvolvem as interações humanas e de estabelecerem conexões abstratas entre o sujeito observado e o meio social em que ele vive. Tanto Freyre quanto Béhague consideram, ao estudar a trajetória de Villa-Lobos, que ele compõe a partir da "essência brasileira" que porta necessariamente - já que nasceu e se formou no Brasil. Wisnik também tenta construir uma legibilidade das ações de Villa-Lobos através de uma compreensão totalizada de seu meio, abrindo mão assim da possibilidade de questioná-las de modo a restituir toda sua complexidade.

Para romper com as leituras abstratas da vinculação entre a trajetória do ator social que observamos, Heitor Villa-Lobos, e as diferentes redes de interdependência a que ele se ligou em diferentes escalas de análise, precisamos, antes de mais nada, de um forte investimento de pesquisa em fontes primárias. Traçar o funcionamento das diferentes configurações sociais às quais o compositor se ligou implica necessariamente explorar atentamente o funcionamento das redes de interdependência que se tornaram significativas para suas ações e sua inserção nestas redes. Assim, precisamos ter informações concretas a respeito de suas origens familiares, do funcionamento dos meios artísticos do Rio de Janeiro (cidade onde viveu sua juventude) na década de 1910, dos meios da música erudita nesta cidade nesta mesma época, de sua inserção no ambiente artístico parisiense ao longo da década de 1920, de sua participação como “músico oficial” do regime Vargas na década de 1930 e de sua participação, já como compositor célebre, no mercado da música erudita norte-americana a partir de meados da década de 1940. Em cada uma destas situações, é necessário buscar fontes que nos informem acerca das relações concretas efetivamente estabelecidas por Villa-Lobos com seus familiares, seus pares no meio musical, os críticos, os financiadores, o Estado - e todos os demais atores que surjam, ao longo da pesquisa, como agentes e instâncias relevantes para a compreensão de suas práticas. Esta análise microssociológica e microhistórica deve então ser confrontada às dinâmicas macro que presidiram a construção de sentido por parte dos atores ligados a estas redes. No espaço deste artigo, é possível apenas delinear em linhas gerais todo este trabalho, que é realizado em detalhes em meu livro a respeito do compositor (Guérios 2009).

Heitor Villa-Lobos era neto de imigrantes espanhóis que chegaram ao Rio de Janeiro no século XIX. Seu pai, Raul, dificilmente teria acesso a uma educação formal de bom nível; mas descoberto ainda no primário por Alberto Brandão, membro da elite carioca próxima ao imperador Dom Pedro II, conseguiu acesso à educação de nível secundário no colégio montado por Brandão em Vassouras, região produtora de café do interior fluminense. A educação secundária era um privilégio no Brasil do século XIX. Raul poderia, através dos contatos que estabeleceu em sua vida escolar, buscar uma inserção, mesmo que marginal, nos meios de elite. Mas tornou-se um erudito, autor de vários livros, e funcionário concursado da Biblioteca Nacional, decidindo investir em seu capital intelectual em detrimento de seu capital social. Era também um amante da música erudita, e organizava sessões de música de câmara em sua casa, tocando clarinete e violoncelo. Heitor, seu primeiro filho homem, foi estimulado desde cedo a tocar este último instrumento. 
Raul faleceu muito jovem, em 1899, quando Heitor tinha 12 anos. A família, que já vivia em condições relativamente modestas (mas confortáveis para o Rio de Janeiro da época), passou a depender do trabalho de sua mãe, Noêmia, que lavava e passava guardanapos para a Confeitaria Colombo. Heitor diria mais tarde que teve que passar a "lutar sozinho" desde muito cedo devido à morte do pai. Os parcos documentos disponíveis a respeito indicam como Heitor tornou-se um violoncelista de pequenos grupos de câmara, tocando em cinemas, companhias de teatro ou em restaurantes. Seu registro como músico profissional data de 1909.

Não há registros de que Villa-Lobos tenha completado os estudos secundários. No Instituto Nacional de Música, está documentada sua inscrição para participar dos cursos noturnos como aluno de violoncelo. Estes cursos, no entanto, foram cancelados - provavelmente por falta de demanda que justificasse sua continuidade. É certo que Villa-Lobos não concluiu sua formação como instrumentista.

Ao mesmo tempo, ele tinha contato próximo com outro meio musical de sua cidade natal, os "chorões". Estes eram boêmios oriundos da classe baixa carioca que criaram uma nova estética musical - a partir, principalmente, dos lundus e maxixes que conheciam. Os "choros" se tornaram uma das formas representativas da música popular carioca. Não há documentos que atestem o grau e a natureza da proximidade de Villa-Lobos com os chorões, mas suas falas, sua posição social na cidade, seus contatos com pessoas deste meio e alguns depoimentos indicam que ele circulava nestes meios boêmios populares com frequência.

Os anos de formação de Villa-Lobos tornam-no, assim, um personagem bastante específico: oriundo dos meios populares, mas em contato com a "alta cultura" em sua casa; músico erudito profissional, mas sem formação clássica; alguém que circulava nos meios da música erudita, mas sempre em contato próximo com a música popular. Esta posição na configuração social de diferentes meios artísticos cariocas iria torná-lo um personagem propício a atuar como um mediador entre eles. Sua opção por desenvolver sua carreira na música erudita, enfim, possibilitou que ele viesse a colocar-se como um produtor de rupturas.

Ao longo da década de 1910, Villa-Lobos iniciou-se como compositor. Sua produção desta década atesta o quanto ele buscava ser aceito nos meios da música erudita carioca. Aqui, entra em questão um segundo nível de análise, aquele que diz respeito não ao ambiente social imediato de Villa-Lobos, mas aos ambientes artísticos da cidade do Rio de Janeiro. Dentro do campo da música, para ser ouvido por seus pares, era necessário que um compositor demonstrasse o domínio das estéticas correntes neste meio. A música popular estava proscrita, vista como música para "assobiadores". O embate estético dava-se entre os seguidores de Wagner, visto como um músico "moderno" e "republicano", e os seguidores da estética lírica italiana, associada à nobreza e à nostalgia em relação ao Império. Villa-Lobos compõe em ambas as linhas: sua Sinfonia no 1 segue a estética vigente no Instituto Nacional de Música, inspirando-se em Wagner e em Vincent D'Indy (compositor francês cujo Cours de composition musicale era adotado no ensino desta instituição); enquanto, ao mesmo tempo, ele compõe uma ópera, Izaht, que segue a estética italiana.

Na medida em que vai se tornando conhecido, no final da década de 1910, Villa-Lobos passa a compor seguindo as regras propostas por Claude Debussy. Debussy era visto como um compositor de "vanguarda" nos 
meios musicais eruditos cariocas: a composição de peças como A Fiandeira, que seria apresentada na Semana de Arte Moderna em São Paulo, indica que Villa-Lobos utilizava Debussy para criar uma distinção em relação a seus pares.

A década de 1910 foi considerada por vários estudiosos de Villa-Lobos como uma época de “imaturidade artística", na qual ele ainda não haveria desenvolvido um estilo próprio. A atenção às características da configuração social de que ele participava, no entanto, fornece informações mais precisas acerca da importância de suas opções estéticas. Já em 1914 ele compôs peças como as Danças características africanas, que incluíam elementos rítmicos ligados à música popular carioca. Estas composições indicam que ele já era então capaz de compor de acordo com a linguagem própria, que desenvolveria mais tarde. Mas para ser aceito por seus pares era necessário deixar esta vertente de lado. Suas composições mostram como ele o fez: optando por destacarse deles ao fazer tudo o que faziam e algo mais, marcando sua posição de vanguarda.

No final da década de 1910, com grandes dificuldades e demonstrando grande habilidade para conseguir recursos, Villa-Lobos conseguiu apresentar suas composições sinfônicas no Rio de Janeiro. Logrou assim inserirse no campo da música erudita local. Era então hora de ir a Paris: a viagem à capital francesa, então o grande pólo artístico europeu, era tida no Brasil como um "passo natural” para um artista talentoso. As representações acerca de Paris como uma metrópole cultural mundial, compartilhadas em vários países nesta época, têm aqui um impacto concreto sobre a trajetória deste ator social. Villa-Lobos conseguiu então apoio de aliados para que o governo lhe concedesse um auxílio financeiro para apresentar suas obras em Paris, e reuniu recursos entre o mecenato carioca para completar o necessário para sua viagem. Em seu embarque para Paris, afirmou em entrevista que iria "não para aprender, mas para mostrar o que fez".

Sua chegada à França, em 1923, demonstraria o quanto ele estava equivocado. Ao inserir-se concretamente nas microrredes de sociabilidade do ambiente artístico parisiense, e, ao apresentar suas composições "de vanguarda" debussyistas, Villa-Lobos rapidamente descobriu que estava defasado no cenário da música erudita parisiense. Nestes meios, desde a apresentação da Sagração da Primavera, de Stravinski, em 1913, Debussy já havia sido relegado a um passado artístico. Esperava-se então que cada artista propusesse grandes rupturas estéticas, e trabalhasse sobre a linguagem de seu campo artístico - não apenas dentro de estéticas já estabelecidas. Villa-Lobos percebeu que nestes meios, sendo oriundo do Brasil, deveria mostrar músicas "brasileiras". Críticos, compositores, artistas de outras áreas e o público - todos pareciam ávidos por ouvir o que poderia ser uma música erudita deste país que inspirava tanto "exotismo". Os depoimentos de Villa-Lobos, as cartas de artistas com os quais conviveu, as críticas aos concertos que apresentou, as publicações de seus pares franceses do campo da música erudita - todas estas evidências empíricas obtidas a partir de um trabalho microhistórico indicam claramente como Villa-Lobos converteu-se, nesta viagem, em um músico "brasileiro". Ao deixar o Brasil, o compositor ainda se apresentaria como um músico erudito de formação clássica; ao voltar de Paris, ele passaria a dar depoimentos emocionados acerca de seu pertencimento e de sua "essência" brasileira. Este processo nos fornece também indicativos preciosos acerca da dinâmica concreta de funcionamento dos fluxos culturais entre 
"centro" e "periferia", não pensados "em termos simples, de força/fraqueza", mas "deslocando a análise para os fenômenos de circulação, de negociação, de apropriação em todos os níveis" (Revel 1998: 29). As relações micro estabelecidas por Villa-Lobos eram tributárias das dinâmicas macro entre os dois países; estas últimas, no entanto, tornam-se visíveis em toda a sua complexidade apenas a partir do momento em que o estudioso enfoca as pequenas interações entre os atores. $O$ resultado final observado nesta análise é que o impacto das redes artísticas parisienses sobre Villa-Lobos foi maior do que o impacto oposto, de Villa-Lobos sobre elas. ${ }^{9}$

Suas composições são o maior testemunho da transformação por que passou em sua viagem a Paris. Até o final da década de 1920, ele criaria um estilo musical inconfundível, resultado de uma habilidosa síntese da estética sinfônica "primitivista" de Stravinski com a música popular carioca e a música indígena brasileira, por ele ouvida em gravações feitas pelo antropólogo Edgar Roquette-Pinto. A "música brasileira" feita por VillaLobos agrega assim em sua substância tanto estéticas musicais diversas quanto as características das redes de interdependências a que estava ligado: seu "Brasil" é uma síntese da música sinfônica de vanguarda em Paris com a música popular que conheceu em sua juventude, e ainda com o "tempero" do exotismo indígena, tão caro aos franceses que Ihe indicaram o caminho da "música nacional". Ao mesmo tempo, Villa-Lobos participa ativamente das relações macro entre os movimentos artísticos brasileiro e europeu, e suas influências recíprocas podem ser traçadas concretamente a partir do estudo de sua trajetória.

No final da década de 1920, Villa-Lobos perdeu sua fonte de financiamento. Os irmãos Arnaldo e Carlos Guinle, milionários cariocas que o sustentaram durante três anos em Paris, cortaram seus auxílios, e, muito a contragosto, o compositor retornou ao Brasil. Nos primeiros anos da década de 1930, suas cartas escritas aos Guinle demonstram o quanto ele ainda desejava voltar a Paris. A estética "primitivista" de Stravinski já havia sido substituída na capital francesa, pelo próprio Stravinski, pela proposta do "neoclassicismo" - a retomada da estética musical clássica, mas em uma nova chave. Vila-Lobos já começava então a compor suas Bachianas brasileiras, aparentemente no intuito de se inserir neste novo ambiente artístico da capital francesa, e aguardava apenas uma forma de viabilizar sua mudança definitiva para lá.

Os concertos que conseguiu agendar, no entanto, estavam longe de lhe aportar os recursos necessários para tanto. Villa-Lobos passou a ter contato próximo com o interventor do Estado de São Paulo, João Alberto Lins de Barros, que era também músico e, segundo depoimentos de pessoas próximas, excelente pianista. A "Revolução de 1930" havia ocorrido, e o viés totalitarista do governo de Vargas servia bem a quem desejava propor grandes projetos. Villa-Lobos aderiu ao ideário da Revolução desde o princípio, e, através de Lins de Barros, conseguiu organizar eventos musicais de proporções que até então pareciam inimagináveis: em uma “concentração cívica" levada a cabo em 1932, por exemplo, reuniu um coral de 12 mil vozes.

O movimento político nacional tinha, mais uma vez, impactos diretos sobre o indivíduo cuja trajetória acompanhamos, e ele seria igualmente ativo na definição de parte de seus rumos: uma configuração macro, resultante de inúmeras pequenas interações, gerava um novo campo de possibilidades, que regulava por sua vez as microrrelações que a constituíam. Ainda em 1932, o compositor colocava em entrevistas que estava à 
disposição de Vargas para implementar um projeto de educação musical de grandes proporções, e logo VillaLobos passou a fazer parte do regime de Vargas como seu "músico oficial". Sua afinidade ideológica com o regime, indicada em suas ações e em seus escritos, casou-se com seus interesses, detectáveis a partir do estudo de sua trajetória e de seus escritos. Até o final do Estado Novo, Villa-Lobos trabalhou intensamente em seu projeto educativo, ao mesmo tempo em que se tornava o "maestro das multidões" em grandes concentrações populares voltadas ao culto da personalidade de Vargas.

Após o final do Estado Novo, com a volta ao Estado de Direito, Villa-Lobos afastou-se de seu cargo oficial. Seus últimos 15 anos de vida ocorreram entre o Brasil e seus compromissos no exterior como compositor já consagrado - e submetido às exigências do mercado internacional de música erudita, ou seja, inserido em outra posição, em outras redes, e ainda ligado a eventos que ocorriam em grande e em pequena escala. O grande pólo cultural deslocou-se de Paris para os Estados Unidos, onde o compositor se apresentou com frequência cada vez maior. Villa-Lobos passou a compor quartetos, forma clássica por excelência, e deixou a estética nacional de lado. ${ }^{10}$

\section{CONCLUSÃO}

A trajetória de vida de Heitor Villa-Lobos parece-nos demonstrar de modo expressivo o rendimento que o estudo de trajetórias, levando em consideração os diferentes níveis de escala do micro ao macro, oferece para a pesquisa. O estudo das redes imediatas a que ele esteve ligado, complementado necessariamente por uma compreensão dos contextos macroscópicos a que estas redes estavam ligadas, é capaz de nos informar tanto acerca das inflexões que tal trajetória sofreu, quanto acerca das condições de possibilidade que delimitaram a expressão musical de Villa-Lobos. Este tipo de proposta analítica apresenta claro contraste em relação às especulações e generalizações abstratas que caracterizam trabalhos feitos a partir de outros paradigmas.

O emprego deste método parece superar algumas das dificuldades encontradas em tais trabalhos. Por um lado, ele revela, em toda sua complexidade, as condições em que ocorreu a construção de uma dada idéia de brasilidade: como sugere a microhistória, uma vida singular permite um olhar mais sofisticado sobre uma época, colocando em questão leituras simplificadoras acerca de dados eventos ou dinâmicas sociais. Por outro lado, permite uma alternativa aos olhares que operam com a alternativa entre "indivíduo" e "sociedade", ao enfocar simultaneamente - mesmo porque são indissociáveis - o indivíduo e as redes sociais de que ele participa.

$O$ estudo de uma trajetória individual nestes termos parece assim ser um locus rico para complexificar nossa compreensão acerca da dinâmica de funcionamento de diferentes configurações sociais em diferentes níveis de análise. Entretanto, isto apenas pode ocorrer sob a condição de que a pesquisa se apoie em uma cuidadosa análise das redes de interdependência nas quais esta trajetória está ancorada, ao mesmo tempo em que se considera a inserção destas redes em um quadro mais geral. Esta estratégia provou-se, no caso 
da pesquisa sobre Villa-Lobos, altamente rendosa para o estudo das mediações entre processos coletivos e percursos individuais, permitindo ao mesmo tempo compreender as dinâmicas de funcionamento de diferentes agrupamentos sociais e das relações estabelecidas entre eles. 


\section{NOTAS}

1 Um primeiro esboço deste artigo foi apresentado como comunicação de pesquisa no GT Pensamento Social no Brasil no 33o Encontro Anual da ANPOCS. Agradeço aos comentários de todos os presentes no GT e às críticas dos pareceristas anônimos da Revista Campos, que auxiliaram na transformação desta comunicação em artigo. Também agradeço especialmente à leitura cuidadosa de Simone Meucci, que em muito auxiliou para diminuir os limites da presente reflexão.

2 Bertaux (1999 [1980]: 2) cita nominalmente, a esse respeito, a teoria funcionalista parsoniana e os métodos estatísticos da survey research. Na França, a influência do estruturalismo de Lévi-Strauss e do viés durkeimiano da Escola dos Annales teve o mesmo efeito.

3 Não trataremos aqui de uma outra vertente do retorno dos estudos de história de vida que se desenvolveu sob um viés hermenêutico ou interpretativo, principalmente nos Estados Unidos. A referência fundamental para esta segunda forma de tratar os relatos de vida, que reúnem-se ao redor do conceito de "narrativa", são os escritos de Paul Ricoeur. Para uma revisão geral deste campo, ver Ochs e Capps, 1996.

4 "As ideias diretrizes de D. Bertaux se expandiram para além do círculo de sociólogos, de maneira direta ou não, nas reuniões de laboratórios e nos colóquios. O enfoque biográfico foi uma referência para muitos pesquisadores (...). Este desenvolvimento, ligado àquele, paralelo, da história oral coincidia com a redescoberta da 'oral history' por homólogos americanos, ingleses ou outros europeus" (Peneff op cit: 26).

5 Percebe-se que, subjacente a ambas as posturas, continua presente a necessidade de justificar a pertinência "científica" do método: se no caso de Bourdieu e Peneff a cientificidade é condição definidora do método, no caso de Bertaux e de Heinich a opção por uma postura tida como qualitativa leva-os a considerar necessária uma defesa explícita da cientificidade de seus trabalhos - seja pela discussão da "generalização" de Bertaux, ou pela negação de Heinich de que seu trabalho seja "subjetivista". De qualquer modo, a proposta de Heinich é problemática ao defender uma postura puramente compreensiva, visto que o próprio Weber não advogou o abandono da explicação em prol da compreensão (ou vice-versa). Como afirma Fleury (2001: 29), "é necessário evitar a dissociação entre compreensão e explicação, [porque] a imputação causal supõe a compreensão e produz compreensão. Em outras palavras, é artificial atribuir a Weber que a compreensão precede a explicação (compreender para melhor explicar), porque Weber pensa igualmente o inverso (explicar para melhor compreender)".

6 Anos após a publicação o próprio Thomas reconheceria, em resposta a uma crítica de Blumer publicada na década de 1930, que, para uma solução analítica adequada para o problema do foco do estudo em relatos individuais, "é evidente que o que é necessário é (...) tanto a coleta continuada de registros de vida de indivíduos (...) quanto a aplicação de estudos estatísticos apropriados, como base para as inferências traçadas. E estas inferências, por sua vez, devem ser continuamente submetidas a análises estatísticas adicionais, para tornar possível transmutar mais fatores em forma quantitativa. A estatística torna-se, assim, o processo contínuo de verificação da formação de hipóteses" (Thomas 1939: 87).

7 Seria possível discutir mais detidamente, se o assunto não escapasse ao escopo do presente artigo, as múltiplas aproximações possíveis entre a sociologia histórica de Elias e o método proposto pelos microhistoriadores. Tal aproximação se reflete claramente na recorrência de estudos que se referem simultaneamente a ambas a propostas analíticas. Para um caso recente, ver o artigo de Gaboriau e Gaboriau (2009), que argumentam que "o olhar e o método que constituem a mudança e a articulação de diversas escalas concordam de modo privilegiado com a análise das formações culturais [proposta por Norbert Elias]".

8 É importante ressaltar, no entanto, que estes autores não tinham o compromisso do uso da história de vida como método. Mesmo assim, é possível perceber em suas análises os pressupostos que os guiam na apreciação da inserção social dos autores observados.

9 Para uma discussão mais detida deste assunto, ver Guérios, 2003

10 Um último projeto de música "nacional" ocorreu apenas a partir de uma demanda de um estúdio de Holly-wood: Villa-Lobos compôs então, logo antes de sua morte, a Floresta do Amazonas. Pela dificuldade de sincronia com as imagens do filme Green Mansions, para o qual foi encomendada, esta bela obra sinfônica foi nele utilizada de forma descaracterizada. 


\section{REFERENCIAS BIBLIOGRAFICAS}

BECKER, H. S. 1986. "Biographie et mosaïque scientifique". In Actes de la recherche en sciences sociales 62-63. BÉHAGUE, G. 1994. Heitor Villa-Lobos. The search for Brazil's Musical Soul. Austin: ILAS / University of Texas. BENSA, Alban. 1998. "Da micro-história a uma antropologia crítica". In J. Revel (org.) Jogos de Escalas: $A$ experiência da micro-análise. Rio de Janeiro: FGV.

BERTAUX, D. 1999 [1980]. “El enfoque biográfico: su validez metodológica, sus potencialidades”. In Proposiciones 29(4): 1-23.

1997. Le récit de vie. Paris: Armand Colin.

BOURDIEU, P. 1986. “L'illusion biographique”. In Actes de la recherche en sciences sociales 62-63.

ELIAS, N. 1980. "Modelos de jogos" e "Características universais da sociedade humana". In Introdução à Sociologia. Lisboa: Edições 70.

ELIAS, N. 1994. A Sociedade dos Indivíduos. Rio de Janeiro: Jorge Zahar.

FLEURY, L. 2001. Max Weber. Paris: PUF.

FREYRE, G. 1962. “Villa-Lobos, pan-brasileiro mas carioca”. In G. Freyre Vida, forma e cor. Rio de Janeiro: José Olympio.

1982. Villa-Lobos revisitado. Transcrição de palestra proferida no Festival Villa-Lobos.

GABORIAU, P. \& GABORIAU, Ph. 2009. “Vers un nouvel artisanat? Quelle enquête pour quel terrain”. Horizontes Antropológicos 15(32): 115-128.

GUÉRIOS, P. R. 2003. “Heitor Villa-Lobos e o ambiente artístico parisiense: convertendo-se em um músico brasileiro". Mana 9(1): 81-108.

2009. Heitor Villa-Lobos. O caminho sinuoso da predestinação. Curitiba: Edição do autor / Parabolé.

HEINICH, N. 2010 “Pour en finir avec I' "illusion biographique"”. In L'Homme 195-196: 421-430.

LEVI, G. 1989. “Les usages de la biographie". In Annales, Économies, Sociétés, Civilisations 44(6): 1325-1336.

1992. "Sobre a micro-história". In P. Burke (org.) A escrita da história: novas perspectivas. São Paulo:

Editora UNESP.

MINTZ, S. 1960. Worker in the cane. New Haven: Yale University Press.

OCHS, E. e CAPPS, L. 1996. "Narrating the self". In Annual Review of Anthropology 25: 19-43.

PASSERON, J-C. 1990. “Biographies, flux, itinéraires, trajectoires”. In Revue française de sociologie 31(1): 3-22.

PENEFF, J. 1994. "Les grandes tendances de I'usage des biographies dans la sociologie française". In Politix 7(27): 25-31. 
QUEIROZ, M. I. P. 1987. “Relatos orais: do 'indizível' ao 'dizível'”. In Ciência e Cultura 39(3): 272-286.

REVEL, J. 1992. "Microanálise e construção do social". In J. Revel (org.) Jogos de escalas. A experiência da microanálise. Rio de Janeiro: FGV.

THOMAS, W. I. 1939. "Comment by W. I. Thomas." In Critiques of Research in the Social Sciences: An Appraisal of Thomas and Znaniecki's "The Polish Peasant in Europe and America [Bulletin 44]. New York: Social Science Research Council.

WISNIK, J. M. 1983 [1974]. O Coro dos Contrários. A música em torno da semana de 22. São Paulo: Duas Cidades. 
O estudo de trajetórias de vida nas Ciências Sociais: trabalhando com as diferenças de escalas

\section{RESUMO}

Este artigo tem por objetivo discutir criticamente a proposta de estudo de histórias de vida iniciada pela "Escola de Chicago" e retomada por estudiosos franceses a partir da década de 1970. Propõe-se uma metodologia de pesquisa que combine esta tradição com uma atenção à variação de escalas, conforme a proposta dos microhistoriadores italianos. Com base em um estudo da trajetória do compositor brasileiro Heitor Villa-Lobos, argumenta-se que tal metodologia permite complexificar a análise das relações entre os sujeitos cujas trajetórias são enfocadas e sua inserção em diferentes ambientes sociais.

PALAVRAS-CHAVE: história de vida; trajetórias; variação de escalas; Heitor Villa-Lobos.

\section{The study of life trajectories in the Social Sciences: working with the differences in scales}

\section{ABSTRACT}

This article discusses the methodology of life stories initiated by the "Chicago School" and taken up by French scholars from the 1970s. It proposes a combination of this tradition with the microhistorians' discussion on the variation of scales. Based on a study of the trajectory of the Brazilian composer Heitor Villa-Lobos, it is argued that this methodology allows to complexify the analysis of the relation between the individual whose trajectory is analyzed and his insertion in different social environments.

KEYWORDS: life story; trajectories; variation of scales; Heitor Villa-Lobos.

Recebido em: 06/06/2011 